Оригинальная статья/Original article

УДК 628.349 .08

DOI: http://doi.org/10.20914/2310-1202-2016-4-245-249

\begin{tabular}{cll}
\hline \hline Анализ эффективности аэротенков в системе очистки сточных вод \\
\hline \hline Зухра Р. Шамсутдинова ${ }^{1}$ & zuhrush92@mail.ru \\
Ильдар И. Хафизов & ${ }^{2}$ & khafizov@kpfu.ru \\
\hline
\end{tabular}

${ }_{1}^{1}$ кафедра биомедицинской инженерии и управления инновациями, Инженерный институт Казанского (Приволжского) федерального университета, ул. Сайдашева, 12, г. Казань, 420021, Россия

${ }^{2}$ Инженерный институт Казанского (Приволжского) федерального университета, ул. Сайдашева, 12, г. Казань, 420021, Россия

Реферат. В работе обсуждается проблема очистки сточных вод нефтехимического производства и предлагаются пути ее усовершенствования. Рассматривается биологический метод, основанный на использовании закономерностей биохимического и физиологического самоочищения рек и других водоёмов. Биологический метод является перспективным в системе очистки сточных вод, благодаря его деструктивности, потому что в результате его происходит частичное или полное разрушение загрязнителей в сточной воде. В статье исследуется интенсивность и результативность такой очистки. Эффективность очистки зависит от степени поддержания бактерий в состоянии физиологической активности. Для этого сравниваются случаи применения процессов одно-, двух- и более ступенчатой очистки с дифференцированной организацией движения воды и ила, а также структурные схемы установок для биологической очистки и процессы, которые сопровождают различные типы очистки. Анализируется эффективность использования аэротенков с максимальной и минимальной зоной регенерации. Выяснили, что при биологической очистке с максимальной зоной регенерации эффективность по химическому потреблению кислорода и скорость окисления выше, чем при режиме с минимальной зоной регенерации. Для решения проблемы эффективной очистки сточных вод предлагается технологическая схема расстановки аэротенков с изменением угла смешения потоков активного ила со сточной водой. Такая технологическая схема полной биологической очистки представляет собой комплекс очистных сооружений, которые располагаются таким образом, что сточная жидкость, проходя их последовательно одно за другим, подвергается механической, биологической очистке и дезинфекции перед спуском ее в водоем.

Ключевые слова: загрязнение, сточные воды, обеззараживание, аэротенки, технология очистки воды, органические примеси, водоемы, промышленные предприятия

\title{
Analysis of the aerotanks efficiency in wastewater treatment system
}

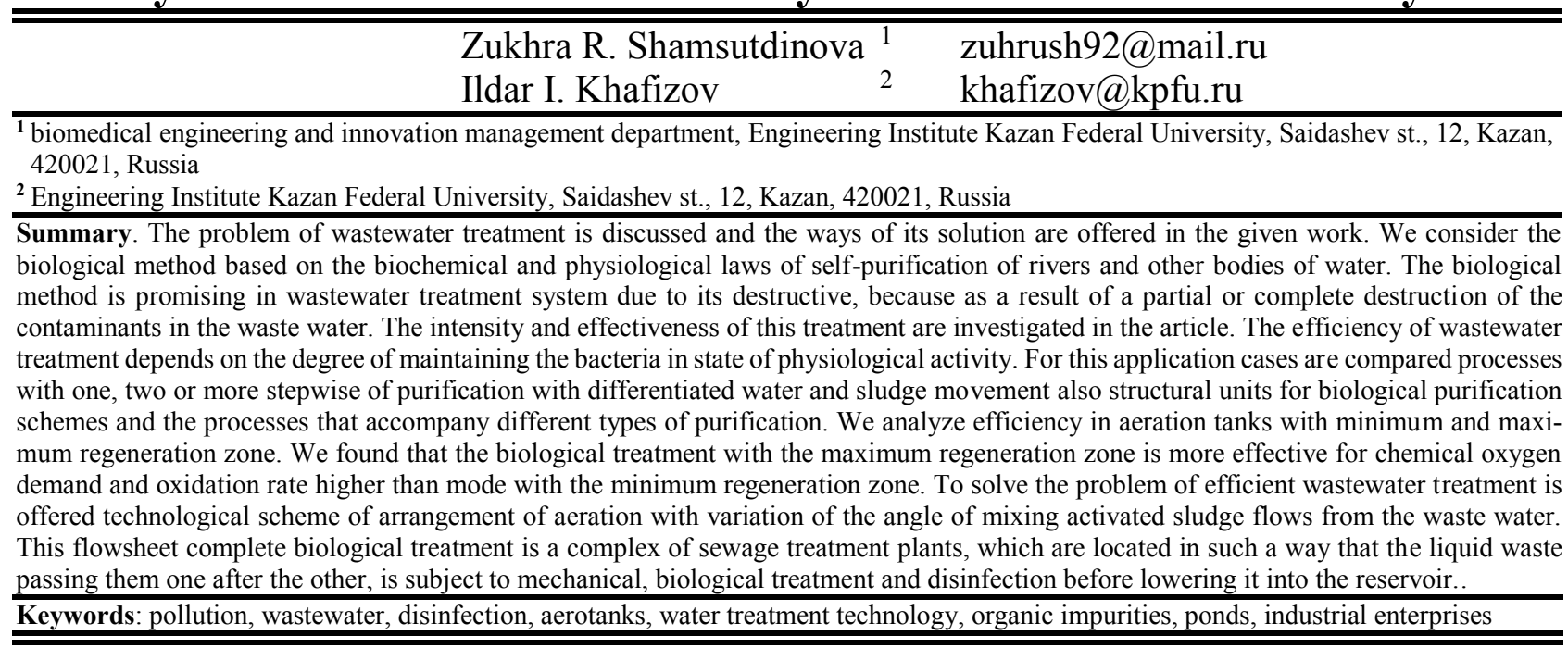

\section{Введение}

Среди методов очистки сточных вод важную роль играет биологический метод, основанный на использовании закономерностей биохимического и физиологического самоочищения рек и других водоёмов. До использования биологического метода сточные воды очищаются механическими и химическими методами, например, хлорируют жидким хлором или хлорной известью.

\section{Для цитирования}

Шамсутдинова 3. Р., Хафизов И. И. Анализ эффективности аэротенков в системе очистки сточных вод // Вестник ВГУИТ. 2016 № 4. C. 245-249. doi:10.20914/2310-1202-2016-4-245-249
Биологический метод очистки основывается на возможности бактерий питаться загрязнителями сточных вод. Особенность микроорганизмов выражается в том, что их клетки состоят из одинаковых с клетками высших растений, животных и загрязнителей воды биогенных элементов и микроэлементов с тем, что в состав их клеток входят те же биогенные элементы и микроэлементы. Таким образом, бактерии являются источником питания животных, обитающих в воде, в то же время они, питаясь, разлагают загрязнители.

\section{For citation}

Shamsutdinova Z. R., Khafizov I. I. Analysis of the aerotanks efficiency in wastewater treatment system . Vestnik VSUET [Proceedings of VSUET]. 2016. no. 4. pp. 245-249. (in Russian). doi:10.20914/23101202-2016-4-245-249 


\section{1 Сущность метода биохимической очистки сточных вод}

По сравнению с очисткой сточных вод адсорбционными методами и ионным обменом биохимический метод деструктивен, потому что в результате его происходит частичное или полное разрушение загрязнителей в сточной воде [1-3].

Высокая биохимическая активность микроорганизмов способствует их употреблению различных веществ и окислительно-восстановительных процессов как источников энергии, что является их преимуществом перед прочими организмами.

Микроорганизмы способны окислять клетчатку, гуминовые вещества, углеводороды. Некоторые их виды преобразуют в энергию восстановленные минеральные соединения, окисляя их. На биоматериале могут также сорбироваться ионы тяжелых металлов и некоторые токсичные соединения.

Энергия, которая выделяется при окислении, используется для биосинтеза вещества клеток бактерий с большой эффективностью. То есть, бактериальная деструкция сопровождается продуцированием биомассы.

В результате использования биохимического метода появляются осадки, с преобладанием минерального и органического содержания, смешанного состава, с содержанием минеральных и органических осадков. Часть не до конца окисленных бактериями органических веществ образуют белковые комплексы, которыми питаются различные представители животного мира водоема. За счет этого происходит минерализация воды.

Непрерывность культивирования бактерий лежит в основе функционирования установок. Принцип действия современных аппаратов основан на методах непрерывного культивирования микроорганизмов (рисунок 1) [4-5].

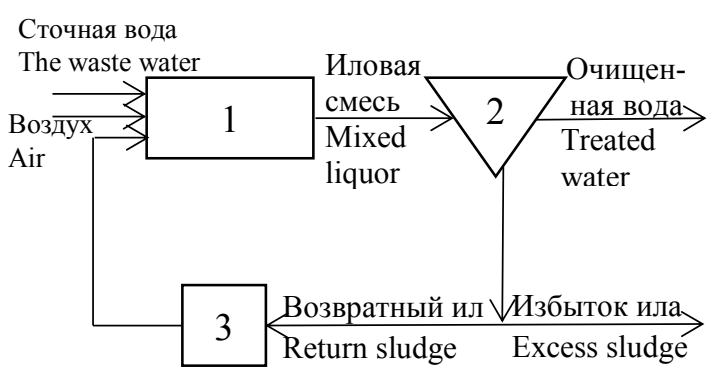

Рисунок 1. Принципиальная схема установки биоочистки с аэротенком: 1 - аэротенк; 2 - вторичный отстойник; 3 - регенератор кнопка

Figure 1. Schematic diagram of installation aeration bioremediation: 1 - aerotank; 2 - secondary clarifier; 3 - regenerator button
Процедура удаления и потребления бактериями органических загрязнителей сточных вод состоит из следующих этапов:

- массопередача органических примесей и кислорода из жидкости к поверхности клетки;

- диффузия вещества и кислорода через полупроницаемую мембрану клеток;

- метаболизм диффундированных веществ, сопровождающийся приростом биомассы, выделением энергии, углекислого газа и т. п.

Этап метаболизма является главным в методе биологической очистки сточных вод. На рисунке 2 показаны наиболее вероятные линии уменьшения концентрации примесей в очищенной воде и изменение массы микрофлоры в зависимости от продолжительности проведения процесса.

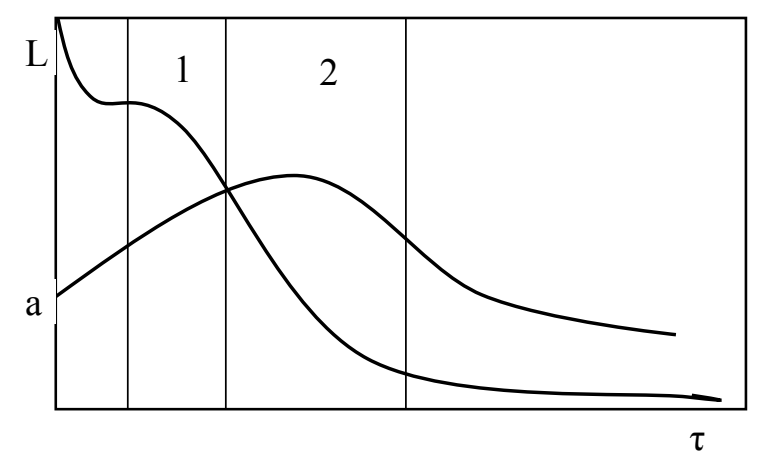

Рисунок 2. Стадии биологического метода очистки сточных вод

Figure 2. Stages of the biological method of sewage treatment

Степень интенсивности и результативности биологического метода очистки зависит от быстроты размножения микроорганизмов. В принципе протекания процесса наиболее характерны две его временные стадии (рисунок 2).

Средняя стадия 2 является «максимально стационарной» и определяется компенсацией увеличения микроорганизмов их отмиранием. На этом этапе физиологическая активность клеток резко снижается и завершается стадия их активного развития.

Результативность очистки зависит от степени поддержания бактерий в состоянии физиологической активности (стадия 1). На этом этапе происходит активное снижение концентрации примесей и одновременный резкий рост объема активных веществ. Эту стадию поддерживает непрерывный проток стоков и постоянные концентрации субстрата [6-7].

Во время проведения биологической очистки протекает биоценоз бактерий (активный ил или биопленка), состав которого находится в зависимости от характера загрязнителей сточной воды, первоначального посевного материала и условий протекания процесса.

В основном фермент, который разъедает примеси, формируется только при непосредственном взаимодействии его с клеткой. 
Это происходит, когда запускаются новые очистные станции или при загрязнении какойлибо новой примесью сточных вод.

Разрушение такой примеси возможно и после несколько месяцев. С целью снижения времени на обработку новых данных при запуске очистных сооружений можно предварительно засеять их уже проверенной и адаптированной микроорганизмами из прочих установок.

Схемы сооружений для биохимической очистки сточных вод могут включать следующие процессы [8]:

- усреднение и осветление исходных сточных вод (усреднители, песколовки, отстойники и т. Д.);

- биохимическая очистка осветленных стоков (аэротенки, регенераторы, вторичные отстойники и т. д.);

- приготовление и дозирование реагентов;

- доочистка очищенных стоков (пруды, фильтровальные станции и т. д.);

- обработка осадков (иловые площадки, фильтры, сушилки и т. д.);

- обеззараживание очищенных стоков.

\section{2 Виды биохимической очистки сточных вод}

Процесс очистки может быть одно-, двухи более ступенчатым (рисунок 3) с дифференцированной организацией движения воды и ила [9]. Это определяется в зависимости от уровня расхода стока, концентрации и природы загрязнителей, требований к качеству очищенной воды.
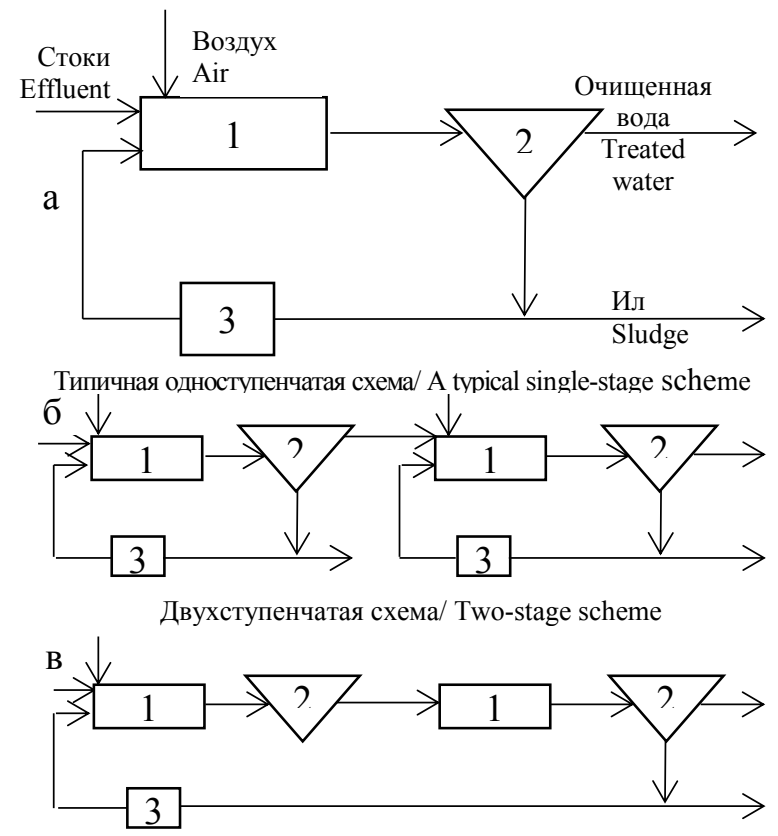

Двухступенчатая схема с рециркуляцией ила

Two stage with recirculation of sludge

Рисунок 3. Различные способы организации биохимической очистки: 1 - аэротенк; 2 - вторичный отстойник; 3 - регенератор

Figure 3. Different ways of organizing biological treatment: 1 - aerotank; 2 - secondary clarifier; 3 - regenerator
В случаях высокой концентрации загрязнителей органического происхождения наиболее оптимальным будет двух- и более ступенчатая схема очистки. При этом на каждом этапе может культивироваться свой биоценоз для отдельной группы загрязнений.

При такой схеме очистки происходит рост результативности очистки, снижение объема установок и расходов на аэрацию, снижение объема извлекаемого избыточного ила, увеличение выдержки аэротенков при резких колебаниях количества и уровня загрязненности исходных стоков.

Установка биохимической взаимосвязана с аппаратами механической, химической, физикохимической очистки и локальными очистными сооружениями. До поступления на биохимическую очистку сточные воды предварительно проходят аварийный амбар, песколовки, нефтеловушки, пруды дополнительного отстоя, песчаные фильтры, флотаторы и т. д. Это проделывается для наиболее полной очистки поступающих стоков до предельно допустимых для биологической очистки концентраций. После завершения этапа подготовки и смешения с промышленными стоками, вода отправляется на двухступенчатую очистку на аэротенках (рисунок 4) [10].

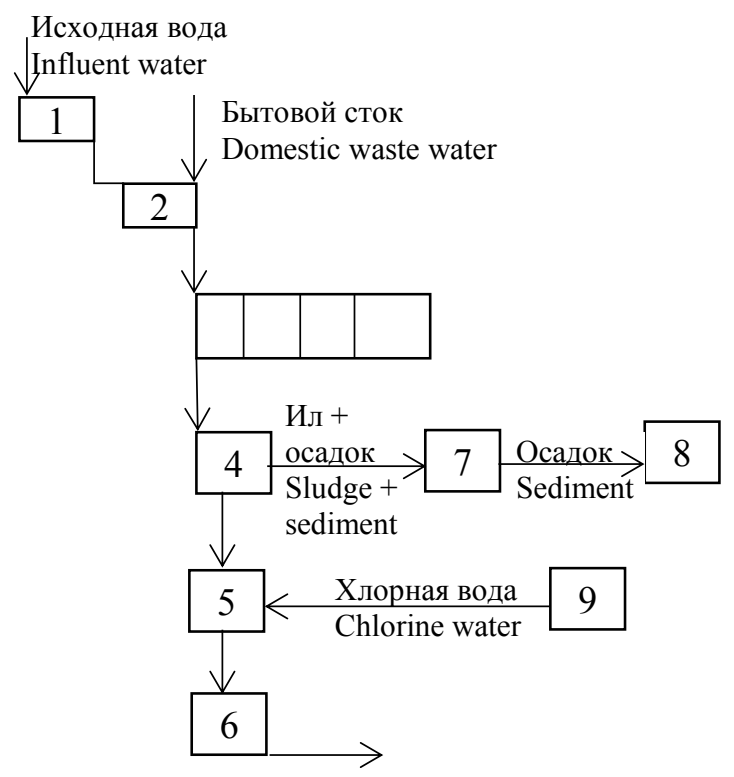

Рисунок 4. Схема компоновки узла биохимической очистки: 1 - усреднитель; 2 - смеситель; 3 - каскад аэротенков; 4 - отстойник; 5 - смешение с хлорной водой; 6 - контактные резервуары; 7 - илоуплотнитель; 8 - метантенк; 9 - склад хлора

Figure 4. Scheme of component units for biochemical treatment: 1 - averager; 2 - adder; 3 - cascade of aerotanks; 4 - clarifier; 5 - mixing with chlorine water; 6 - contact tanks; 7 - sludge consolidation tank; 8 - methane-tank; 9 - chlorine stacker

После завершения первой ступени очистки эффективность удаления органических примесей достигает от 60 до 70\%, после второй - до 95\%. 
По завершении этого этапа очищенные стоки поступают в биофильтры, до сброса их в водоем - в контактные резервуары для обеззараживания.

2 Результаты анализа по очистке сточных вод

Для определения эффективности биохимической очистки такой схемы провели анализ

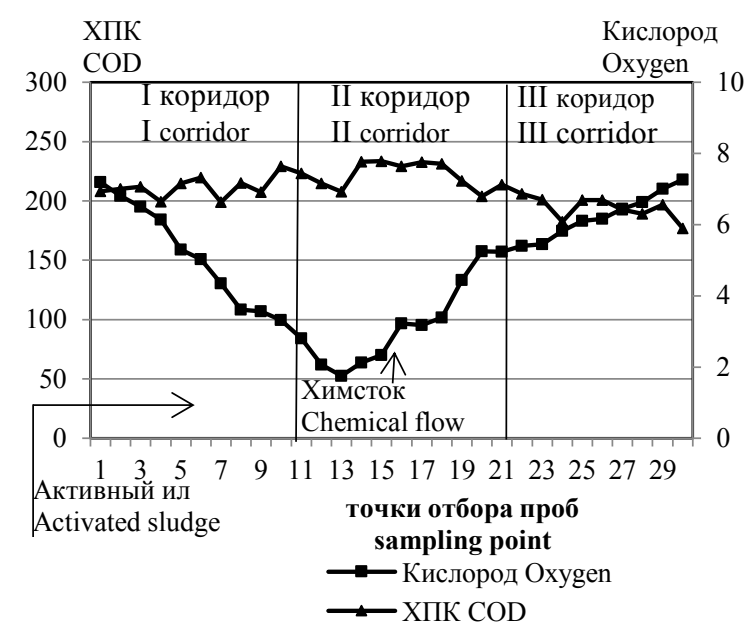

a) результатов очистки по ХПК и О2 при двух вариантах объемов регенерации.

Как видно из результатов анализа, при биоочистке с максимальной зоной регенерации эффективность по ХПК и скорость окисления выше, чем при режиме с минимальной зоной регенерации (рисунок 5).

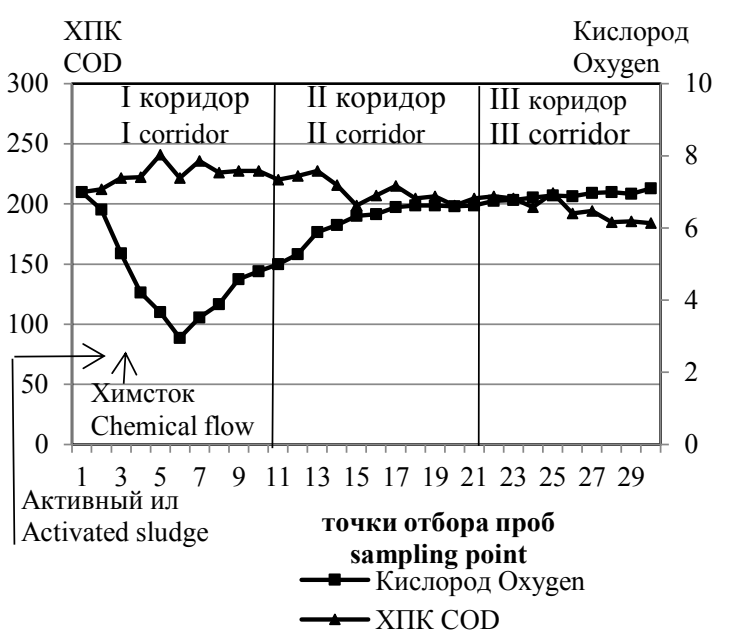

б)

Рисунок 5. Кривые распределения О2 и ХПК по длине аэротенка: $\mathrm{a}$ - с максимальной зоной регенерации (43\%); б - с минимальной зоной регенерации $(4,3 \%)$

Figure 5. Distribution curves $\mathrm{O}_{2}$ and chemical oxygen demand the length of the aerotank: a - maximum regeneration zone $(43 \%) ; b$ - minimum regeneration zone $(4,3 \%)$

Как показано на рисунке 5 по длине зоны биоокислительного процесса, максимальное значение ХПК и наименьшее содержание $\mathrm{O}_{2}$ в смеси находится на уровне сечения впуска сточных вод.

Снижение количества $\mathrm{O}_{2}$ и возрастание ХПК на этапе ввода стоков объясняется разбавлением смеси химическим стоком и увеличением скорости окисления, а также потреблением $\mathrm{O}_{2}$ на окисление субстрата. Такие причины обусловлены недостаточностью перемешивания смеси.

Недостаточность перемешивания смеси происходит из-за того, что потоки активного ила подаются под углом 900 точечно с торца коридора аэротенка. Таким образом, сосредоточенная подача циркуляционного ила и рассредоточенная подача стоков через окна не позволяют эффективно смешивать стоки, ил, воздух, подтверждением чего являются падение кислорода и резкий скачок ХПК на кривых распределения $\mathrm{O}_{2}$ и ХПК (рисунок 5) по длине аэротенка с рассредоточенной подачей химстока.

Для улучшения перемешивания активного ила с химстоком и повышения результативности очистки воды, предлагается следующая технологическая схема очистки сточных вод.

В технологическую схему полной биологической очистки включены сооружения для его специальной обработки.

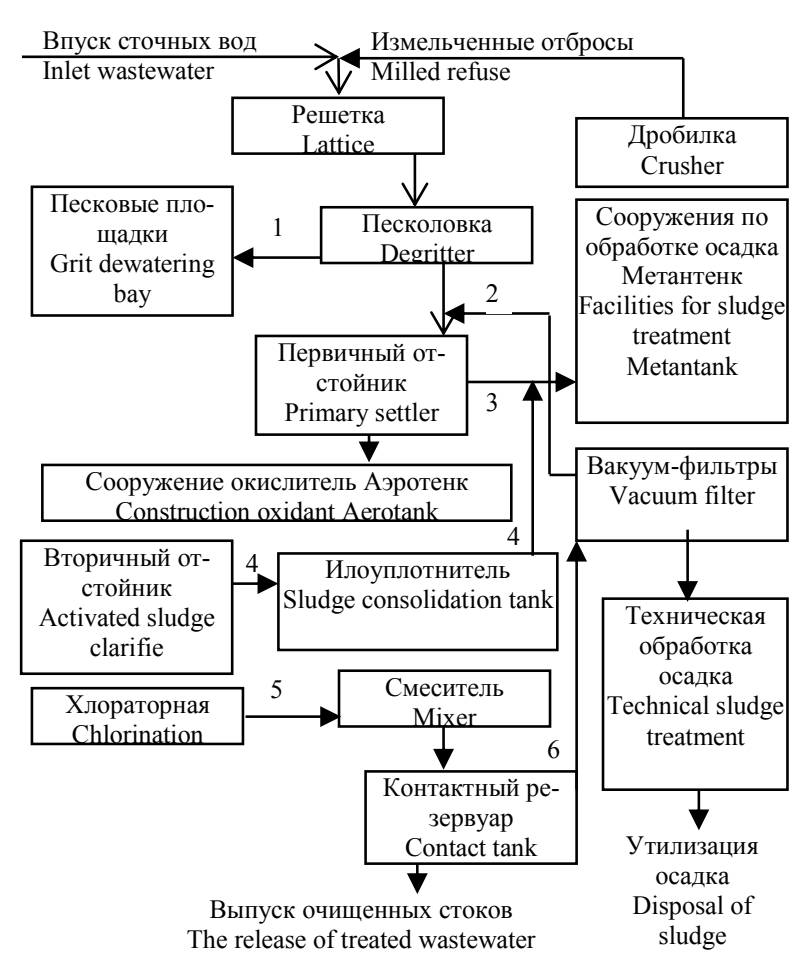

Рисунок 6. Технологическая схема полной биологической очистки сточных вод: 1 - песчаная пульпа, 2 - иловая вода, 3 - осадок, содержащий органику, 4 - ил, 5 - хлорная вода, 6 - осадок

Figure 6. Technological scheme of complete biological wastewater treatment: 1 - sand slurry, 2 - sludge water, 3 - precipitate containing organics, 4 - sludge, 5 - chlorine water, 6 - settling 
Технологическая схема полной биологической очистки представляет собой комплекс очистных сооружений, которые располагаются таким образом, что сточная жидкость, проходя

\section{ЛИТЕРАТУРА}

1 Wunderlin P. Mechanisms of $\mathrm{N}_{2} \mathrm{O}$ production in biological wastewater treatment under nitrifying and denitrifying conditions // Water Research. 2012. P. 1027-1037.

2 Каратаев О.Р., Новиков В.Ф., Шамсутдинова 3.Р. Моделирование процессов растворения химических реагентов в потоках воды // Вестник Казанского технологического университета. 2013. № 22. С. 45-47.

3 Кадырова А.М. Биохимические основы методов биологической очистки сточных вод// Научный вестник технологического института. 2014., № 13. С. 315-326.

4 Минаева Л.А., Дударев В.И. Современные методы деманганации природных и сточных вод// Известия вузов. Прикладная химия и биотехнология. 2014. № 5 (10). С. 76-81.

5 Назаров В.Д., Назаров М.В. Глубокая очистка нефтесодержащих вод с применением искровых разрядов // Защита окружающей среды в нефтегазовом комплексе. 2015. № 9. С. 12-16.

6 Popowich A., Zhang Q., Le X.C. Removal of nanoparticles by coagulation // Journal of Environmental Sciences. 2015. P. 168-171

7 Westerhoff P.K., Kiser M.A., Hristovski K. Nanomaterial removal and transformation during biological wastewater treatment // Environmental Engineering Science. 2013. P. 109-117.

8 Puay N.-Q. Effect of Zinc oxide nanoparticles on biological wastewater treatment in a sequencing batch reactor // Journal of Cleaner Production. 2015. P. 139-145.

9 Dongbo W., Yinguang Ch. Critical review of the influences of nanoparticles on biological wastewater treatment and sludge digestion // Critical Reviews in Biotechnology. 2016. P. 1-13.

10 Елифанов В.Д. Микробиология сточных вод // Международный научный журнал Альтернативная энергетика и экология. 2014. № 18. С. 70-76.

\section{СВЕДЕНИЯ ОБ АВТОРАХ}

Зухра Р. Шамсутдинова студент, кафедра биомедицинской инженерии и управления инновациями, Инженерный институт Казанского (Приволжского) федерального университета, ул. Сайдашева, 12, г. Казань, 420021, Россия, zuhrush92@mail.ru

Ильдар И. Хафизов к .т. н., заместитель директора по образовательной деятельности, Инженерный институт Казанского (Приволжского) федерального университета, ул. Сайдашева, 12, г. Казань, 420021, Россия, khafizov@kpfu.ru

\section{КРИТЕРИЙ АВТОРСТВА}

Зухра Р. Шамсутдинова обзор литературных источников по исследуемой проблеме, провела анализ, выполнила расчёты Ильдар И. Хафизов консультация в ходе исследования

\section{КОНФЛИКТ ИНТЕРЕСОВ}

Авторы заявляют об отсутствии конфликта интересов.

ПОСТУПИЛА 26.10 .2016

ПРИНЯТА В ПЕЧАТЬ 21.11.2016 их последовательно одно за другим, подвергается механической, биологической очистке и дезинфекции перед спуском ее в водоем.

\section{REFERENCES}

1 Wunderlin P. Mechanisms of $\mathrm{N}_{2} \mathrm{O}$ production in biological wastewater treatment under nitrifying and denitrifying conditions. Water Research. 2012, pp. 1027-1037.

2 Karataev O.R., Novikov V.F., Shamsutdinova Z.R. Modelling of processes of dissolution of chemicals in water flows. Vestnik KGTU [Bulletin of Kazan Technological University] 2013, no. 22. (in Russian).

3 Kadyrova A.M. Basis of biological wastewater treatmen. Nauchnyi vestnik tekhnologicheskogo instituta [Scientific Bulletin of Institute of Technology] 2014, no. 13, pp. 315-326. (in Russian)

4 Minaeva L.A., Dudarev V.I. Modern methods of natural water and sewage demanganization. Izvestiya vuzov [Proceedings of the universities. Applied Chemistry and Biotechnology] 2014. no 5 (10). pp. 76-81. (in Russian)

5 Nazarov V.D., Nazarov M.V. Deep purification of oil-containing waters with application of spark categories. Zashchita okruzhayushchei sredy [Environmental protection in the oil and gas industry] 2015. no 9. pp 12-16. (in Russian)

6 Popowich A., Zhang Q., Le X.C. Removal of nanoparticles by coagulation. Journal of Environmental Sciences. 2015, pp. 168-171.

7 Westerhoff P.K., Kiser M.A., Hristovski K. Nanomaterial removal and transformation during biological wastewater treatment. Environmental Engineering Science. 2013. pp. 109-117.

8 Puay N.-Q. Effect of Zinc oxide nanoparticles on biological wastewater treatment in a sequencing batch reactor. Journal of Cleaner Production. 2015. pp. 139-145.

9 Dongbo W., Yinguang Ch. Critical review of the influences of nanoparticles on biological wastewater treatment and sludge digestion. Critical Reviews in Biotechnology. 2016. pp. 1-13.

10 Epifanov A.V. Microbiology of wastewater. Al'ternativnaya energetika i ekologiya [International scientific journal life and ecology] 2014. no 18, pp. 70-76 (in Russian).

\section{INFORMATION ABOUT AUTHORS}

Zukhra R. Shamsutdinova student, Biomedical Engineering and Innovation Management department, Engineering Institute Kazan Federal University, Saidashev st., 12, Kazan, 420021, Russia, zuhrush92@mail.ru

Ildar I. Khafizov candidate of technical sciences, deputy director of the educational part, Engineering Institute Kazan Federal University, Saidashev st., 12, Kazan, 420021, Russia, khafizov@kpfu.ru

\section{CONTRIBUTION}

Zukhra R. Shamsutdinova review of the literature on an investigated problem, conducted analysis, performed computations

Ildar I. Khafizov consultation during the study

CONFLICT OF INTEREST

The authors declare no conflict of interest.

RECEIVED 10.26.2016

ACCEPTED 11.21.2016 